\title{
Trends and Constraints on Brazilian Photovoltaic Industry: Energy Policies, Interconnection Codes, and Equipment Certification
}

\author{
Fernando Pinhabel Marafão ${ }^{\circledR}$, Member, IEEE, Augusto Matheus dos Santos Alonso ${ }^{\circledR}$, Student Member, IEEE, \\ Flávio A. S. Gonçalves, Danilo Iglesias Brandão ${ }^{\mathbb{0}}$, Member, IEEE, Antonio Cesar Germano Martins, \\ and Helmo Kelis Morales Paredes ${ }^{\circledR}$, Senior Member, IEEE
}

\begin{abstract}
After years of dormant scenarios, the Brazilian industry of photovoltaic (PV) energy systems is now growing fast. Therefore, improving interconnection and certification codes, as well as standards, has become undeniably important to establish a well-regulated market under concern of businesses, equipment, and power quality matters. Thus, considering international standards and world-recognized scenarios for distributed PV systems, this paper aims to discuss the existing local energy regulations, grid connection codes, and other related limitations that restrain a faster market and technology development in Brazil. Special attention is given to the certification requirements for grid-connected inverters and other PV equipment, along with the new trends in energy policies, focusing on their impacts on Brazilian PV industry. In the end, it demonstrates that despite its current underdeveloped status, the Brazilian scenario is expected to be quite enthusiastic in the following years and may represent an attractive and dynamic market for professionals, companies, and energy investors.
\end{abstract}

Index Terms-Brazilian distributed generation rules, distributed generation, energy policies, microgeneration, photovoltaic (PV), PV certification, PV equipment, renewable energy.

\section{INTRODUCTION}

$\mathbf{T}$ HE STEADY growth of world energy demand in the last decades and the related environmental effects of energy production based on fossil fuels have driven the society to consider more and more the importance of renewable energy sources (RES) [1]. In such a context, the movement toward distributed

Manuscript received October 7, 2017; revised January 26, 2018; accepted March 31, 2018. Date of publication May 3, 2018; date of current version September 17, 2018. Paper 2017-CSC-0945.R1, presented at the 2017 Annual IEEE Green Technologies Conference, Denver, CO, USA, Mar. 29-31, and approved for publication in the IEEE TRANSACTIONS ON INDUSTRY APPLICATIONS by the Codes and Standards Committee of the IEEE Industry Applications Society. This work was supported by the São Paulo Research Foundation (FAPES) under Grant 2016/08645-9 and Grant 2017/22629-9. (Corresponding author: Fernando Pinhabel Marafão.)

F. P. Marafão, A. M. dos Santos Alonso, F. A. S. Gonçalves, A. C. G. Martins, and H. K. Morales Paredes are with the Group of Automation and Integrated Systems, Universidade Estadual Paulista, Sorocaba 18087-180, Brazil (e-mail: fernando.marafao@unesp.br; augusto.alonso@unesp.br; flavio.as.goncalves@ unesp.br; antonio.martins@unesp.br; helmo.paredes@unesp.br).

D. I. Brandão is with the Graduate Program in Electrical Engineering, Federal University of Minas Gerais, Belo Horizonte 31270-901, Brazil (e-mail: dibrandao@ufmg.br).

Color versions of one or more of the figures in this paper are available online at http://ieeexplore.ieee.org.

Digital Object Identifier 10.1109/TIA.2018.2833422 generation systems (DGSs) has been consolidated [2]-[5] and highly decentralized and diversified. Power generation systems have become key players in maximizing the energy supply capability. Therefore, RES and DGS technologies are fundamental concepts of achieving high levels of flexibility on power sources.

Hence, considering the importance of such energy trends, the Brazilian government and its federal agencies have been discussing and redefining several rules for the electrical sector [6], mostly based on the rising attractiveness of RES and DGS [7], and obviously aiming at economic growth. Nevertheless, although previous regulations proposed by the Brazilian Electricity Regulatory Agency (ANEEL) [6], [7] intended to boost the sector with updates on interconnection and metering codes, power quality requirements, stability and other matters, still need to be further developed by local rules to offer more consistent conditions for the related users.

Therefore, this paper aims at discussing the Brazilian existing grid connection codes for distributed generators, and also the related limitations delaying a faster market and technology development, by means of comparing them to international standards and well-established markets of photovoltaic (PV) systems. Special attention is given to the certification process of grid-connected inverters and PV modules, also examining new trends in local energy policies, highlighting their likely effects on Brazilian PV industry. Compared to [8], this work brings updated data and expands the analysis from microgeneration to include mini and central generation power plants and shows how dynamic has been the PV industry in Brazil, with significant modifications in a short period of time. Furthermore, a wider discussion is made in regard to governmental regulatory perspectives, also reporting not previously considered information related to the certification of battery charge controllers. Finally, it presents more technical discussions on the matter of inverter design requirements and their contrasts to other standards.

\section{ENERgy Policies AND Related ISSUES}

One of the most important advances in Brazilian guidelines for DGS and RES came from rule 482/2012 [9], which originally allowed the insertion of generation units up to $1 \mathrm{MW}$ to the grid, considering the possibility of net metering. In fact, net metering in Brazil was defined on energy credit basis (not cash basis), 
initially valid for 36 months. Energy credits are defined as a virtual revenue, which is attained upon the selling of energy to the interconnected distribution systems operator (DSO) and can be used for payments/discounts in future electricity bills, being calculated on a relation of cost per kilowatt injected.

In 2015 , the rule 482/2012 was updated by REN 687/2015 [10], affecting the levels of maximum power generation allowance, being extended to $5 \mathrm{MW}$, and also amplifying credit expiration time for 60 months. This provision imposes that, from the moment credits are earned, they must be used to compensate the difference between the consumed and generated power only within this specific window. Other important improvement on REN 687 is the possibility of exchanging energy credits among installations under the same taxpayer registration number. It means that an installation with exceeding generation may use its energy credits to reduce the energy bill in other installation site of the same owner.

Thus, according to [10] and considering the location, infrastructure, and primary energy capability, the DGS can be applied and characterized in three different levels in Brazil. The first is defined as microgeneration and targets energy producers up to $75 \mathrm{~kW}$, comprising mostly residential and commercial installations with PV systems. A second classification starting from $75 \mathrm{~kW}$ is called minigeneration, reaching maximum power capacities of either $3 \mathrm{MW}$, if hydropower plants were considered, or $5 \mathrm{MW}$ in the case of any other renewable resources. Such a level is usually constituted of industries and multiple units of small generators, striving for energy self-sufficiency or economic rewards. A final classification is then determined as central generation plants (CGPs), which are systems with capacities over the minigeneration limits, as in larger industries, clusters of generators, and even utilities/distributors owning power plants, intending financial profits from trades in the electricity market.

In the light of these power-level classifications, looking at the recently published ten-year Energy Expansion Plan [7], it is estimated that the national generation capability from new CGPs will reach up to $10 \mathrm{GW}$, whereas DGS may reach up to $3.5 \mathrm{GW}$, being considered a very conservative number according to the Brazilian Association on PV Solar Energy (ABSOLAR) that estimates the country's potential to be about $160 \mathrm{GW}$, just assuming the existing roof tops.

Currently, in terms of financial incentives leading to the obtainment of such potentials, there is a larger number of energy policies focused on both minigeneration and CGP than on microgeneration. CGPs are particularly induced by public bids, which consider from two- to four-year periods for starting the generation on an electricity contract concession ruled by the government. Minigeneration projects are usually supported by public or private bank's financing at very low interest rates. Both sorts of incentives seem to be worthy energy policies and are starting to show positive results by attracting investments in technology and industrial development, especially when coordinated with some level of nationalization of the technologies involved. At these power and voltage levels, the payback time for PV installations, for instance, is usually lower than six years, and the interconnection codes are not quite different from those already in use for the utilities, as discussed in the next sections.
On the other hand, microgeneration projects still need more attention in terms of financial support, being usually funded by the residential/industrial owners without any kind of financing. Besides, such owners face significantly high interest rates, resulting in long payback periods, what consequently slow down the local microgeneration (and smart grid) eagerness and market expansion. However, from the metering revenue point of view, an indirect revision proposed on the rule REN 733/2016 [11], with execution starting in 2018, may encourage low-voltage consumers to install PV systems (with and without energy storage) in the next few years. This rule intends to offer to consumers the opportunity to choose between the so-called white tariffs, in which the cost of energy varies three times along the day during week days, differently from what is applied nowadays based on fixed values. Electricity prices become more expensive in peak demand hours, therefore encouraging the creation of new prosumers since higher economic benefit is achieved from selling energy in peak hours (i.e., peak shaving technique).

Further advances in policies have been discussed in the previous years, such as tax reduction for equipment and energy trades focused on the RES. In this context, most of the Brazilian states have recently signed an agreement to waive tax collection over the energy credits regulated by REN 687/2015. However, other federal taxes are still applied, such as the social integration program and the contribution to social security financing. To give a broad idea of the market unattractiveness related to taxes, particularly for PV equipment, additional import taxes are expected to be around $12 \%$ for PV modules and $14 \%$ for inverters [12]. Although these tributes directly affect product's prices and the energy business, no additional explanation is made here, due to the intense discussion required for this subject.

From a technological view and brainstorming future scenarios, some governmental regulatory movements as [6] started to discuss the application of grid-tied inverters with ancillary services in the DGS, although not explicitly considered such as already ruled around the world [13]-[14]. Yet, on the negative side of this paradigm, other matter that has been pointed as a relevant drawback for PV investments in Brazil is the lack of qualified personnel offering technical services.

A small number of qualified companies and professionals are responsible to attend the intense demand; therefore, the prices have been more expensive than they were supposed to be. Greater and more decentralized availability of technical educational institutions specialized on matters of the energy sector is required in Brazil, similar to what occurred in the U.K. [15]. Initiatives as the one from the government of India, which implemented the "Sector Skill Council for Green Jobs" [16] for qualifying professionals of the energy sector, creating jobs, and developing universities, standards, and equipment certification centers, would certainly boost the Brazilian perspective.

\section{INTERCONNECTION CODES}

As a result of this intense process of updating regulations, several documents that ruled the Brazilian energy sector, defined as PRODIST [17], were revised for the sake of facilitating the access to microgeneration and regulating their operations. Among 


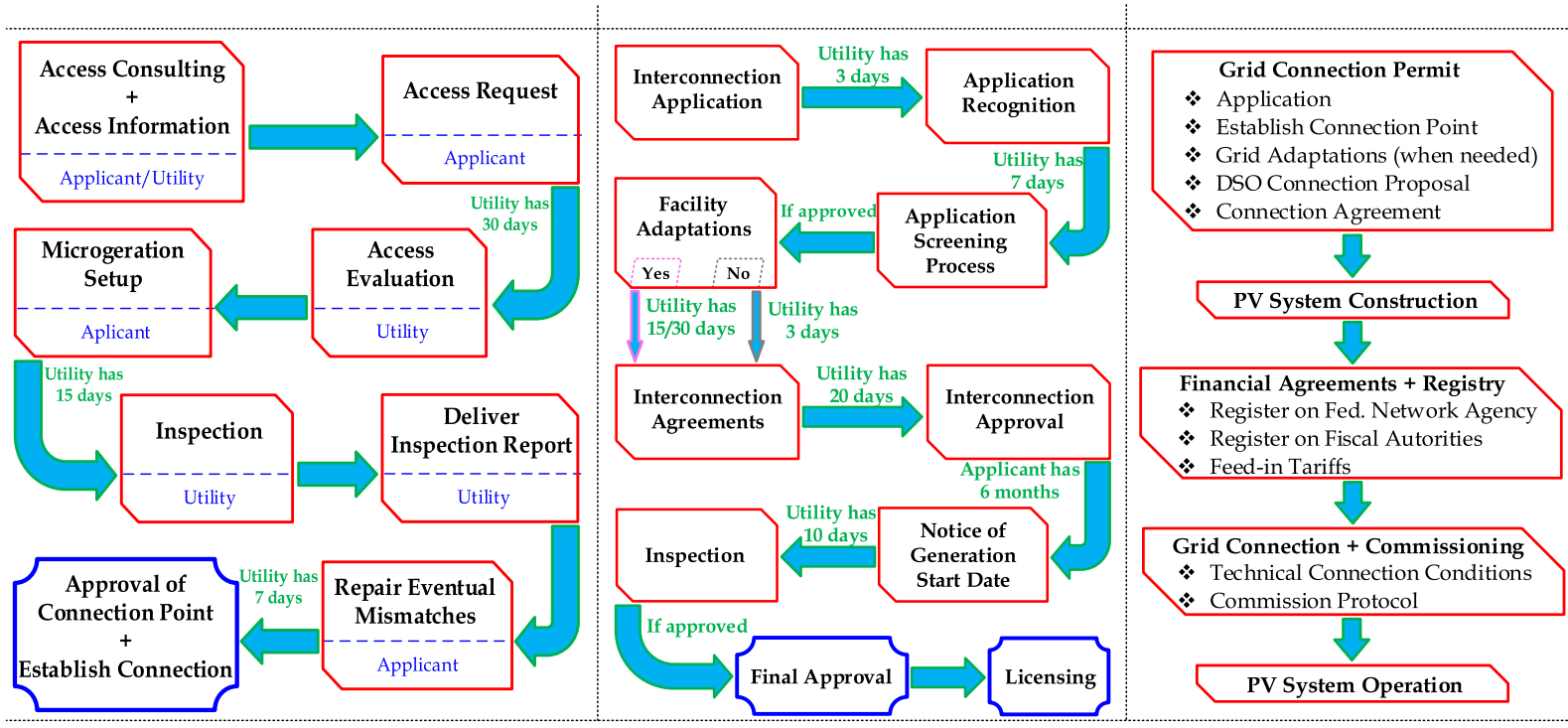

Fig. 1. Fluxogram for the procedures of microgeneration interconnection under the Brazilian, American, and German perspectives.

the nine PRODIST modules, the most significant changes to this section come within the third module [18], which determines the rules for accessing power distribution systems. The Brazilian regulations for the accreditation of a micro- or mini-generation system mostly establish basic rules to be strictly complied with, so, afterwards, power utilities may conduct their own procedures in accepting the interconnection of PV generators and their grids. In brief, the regulatory process for accessing grids with micro/mini generators is split into the following four steps.

1) Access consulting: At this stage, the applicant for the DGS that requests access to a DSO's grid is supposed to contact the local energy provider to formalize the evaluation procedure for identifying if the access point is adequate with respect to the grid infrastructure. A positive answer from the utility is expected by the next stage.

2) Access information: After step 1, the DSO should provide the applicant with the essential information regarding the requirements for such a generation unit to interconnect at the requested electrical node or other alternative suggested points. Along with it, the applicant's power system is classified into a group, which reflects on its responsibilities and costs. Then, initial technical studies related to the impact of the power generation specifications on the grid must be performed by the utility.

3) Access request: This stage consists in formal access application, in which the applicant for the DGS requests the utility to evaluate the candidate's micro- or minigeneration project. The applicant should provide all information related to technical features of the generation plant, the infrastructure project, control and metering instrumentation, and, still, a power production planning. Systematic studies regarding the power quality, which are further explained on the eighth PRODIST module [19], must be conducted by the DSO.

4) Access evaluation: At this last stage, the three previous stages are tied through a decision from the utility regarding the approval for interconnecting the generation system. Having or not a need for infrastructural adaptations in the facilities, specific deadlines are given. To conclude the end of the process, contracts referring to interconnection conditions and economic relations must be signed from both parts (the DSO and the applicant).

All these steps to interconnect a DGS have specific time conditions to occur and are framed according to REN 687/2015. Fig. 1(a) schematically shows how the accessibility process and the time schedule should proceed. Although the relationship between applicants and DSOs may seem to be straightforward, once generation systems with higher power generation capacity are planned, the bureaucracy to obtain access to a connection point gets heavier and other conditions are applied. The previous four access steps still exist in this context, with the particularity of requiring more elaborated evaluations within each of them. For instance, after the first two steps (i.e., access consulting plus information), instructions concerning the most adequate connection point is reported by the utility to the applicant based on a minimum global cost criterion. Such a process takes into account the lowest investment (for applicants and utilities, considering also the minimum cost due to electrical losses) given by the impact analysis of the possible concession of interconnection. Yet, the higher the power capability is, the stricter is the need for more elaborated studies on environmental impacts.

Furthermore, before formally requesting access, a CGP is supposed to apply for a regulatory grant at ANEEL, seeking authorization of exploitation of generation installations for commercializing electricity out of public bids, and further revision in granted authorizations for commerce in any environment. Of course, depending on evaluations from ANEEL, longer timelines of up to one year may occur until the access request step. The main particularity of the last two steps (i.e., access request plus evaluation), beyond heavier paper work, is the necessity to perform intensive studies about the electrical operation impacts on the main grid. Moreover, deeper technical evaluation of 
TABLE I

SPECIFICATIONS OF INTERCONNECTION REQUIREMENTS

\begin{tabular}{|c|c|c|c|c|}
\hline \multirow{2}{*}{ Specification } & \multicolumn{4}{|c|}{ Installed Power of the Generation Unit } \\
\hline & $\mathrm{P} \leq 75 \mathrm{~kW}$ & $75 \mathrm{~kW}<\mathrm{P} \leq 500 \mathrm{~kW}$ & $500 \mathrm{~kW}<\mathrm{P} \leq 5 \mathrm{MW}$ & $\mathrm{P}>5 \mathrm{MW}$ \\
\hline Voltage Interconnection Level* & LV & LV / MV & $\mathrm{MV} / \mathrm{HV}$ & $\mathrm{MV} / \mathrm{HV}$ \\
\hline $\begin{array}{l}\text { Time to Establish Connection } \\
\text { After Final Approval of } \\
\text { Interconnection Application }\end{array}$ & $\begin{array}{l}\text { LV: } \\
3 \text { Business Days (urban area) } \\
5 \text { Business Days (rural area) }\end{array}$ & $\begin{array}{l}\text { LV: } \\
3 \text { Business Days (urban area) } \\
5 \text { Business Days (rural area) } \\
\text { MV: } \\
10 \text { Business Days }\end{array}$ & $\begin{array}{l}\text { MV: } \\
10 \text { Business Days } \\
\text { HV: } \\
15 \text { Business Days }\end{array}$ & $\begin{array}{l}\text { MV: } \\
10 \text { Business Days } \\
\text { HV: } \\
15 \text { Business Days }\end{array}$ \\
\hline $\begin{array}{l}\text { Disconnection + Interruption } \\
\text { Devices }\end{array}$ & Yes & Yes & Yes & Yes \\
\hline Coupling Transformer & No & Yes & Yes & Yes \\
\hline $\begin{array}{l}\text { Under/Over (Voltage and } \\
\text { Frequency) Protection }\end{array}$ & Yes & Yes & Yes & Yes \\
\hline Current Imbalance Protection & No & No & Yes & Yes \\
\hline Voltage Unbalance Protection & No & No & Yes & Yes \\
\hline Directional Overcurrent & No & Yes & Yes & Yes \\
\hline Anti-islanding & Yes & Yes & Yes & Yes \\
\hline
\end{tabular}

*Advisable Levels for Intercon.: HV: $69 \mathrm{kV}$ or $138 \mathrm{kV} / \mathrm{MV}: 13.8 \mathrm{kV}$ or $34.5 \mathrm{kV} / \mathrm{LV}: 3-\Phi(220 / 127 \mathrm{~V}$ or $380 / 220 \mathrm{~V})$ and $1-\Phi(254 / 127 \mathrm{~V}$ or $440 / 220 \mathrm{~V})$

equipment compliance must occur, demanding stricter project requirements. A briefing of technical requisites and features ruled by [18] with respect to safety and operational conditions is shown in Table $\mathrm{I}$.

Now, aiming at discussing some contrasts under an international perspective, taking the USA and Germany as examples, some definitions may differ from the Brazilian interconnection regulations. First, the American perspective, as discussed in [20], varies in each state, and interconnection procedures are mainly defined by utilities. However, some procedures from institutions such as the Interstate Renewable Energy Council are primarily taken as instructions for regulations. Fig. 1(b) summarizes the process for attaining a certified interconnected license for a DGS in the USA.

In Germany, there is no current decree, as in Brazil, or other orientations, such as the one mentioned for the USA; therefore, DSOs are the only responsible for determining the interconnection procedures and timeframe for grid access and legal documentation for commissioning a DGS. The Renewable Energy Act is the only governmental intervention, being not focused on technical issues, ruling only that utilities should give priority in grid access to small RES, also regulating feed-in tariffs, and stating that the DSOs must analyze interconnection applications immediately.

Since each DSO adopts its particular rules, the steps for a PV-based DGS to interconnect in Germany are generalized in Fig. 1(c) and can be further explored in [21]. A grid interconnection permit is attained in five substeps, comprising administrative requirements imposed by the utility. Then, after having the DGS installed, there is a step responsible for the legal financial agreements between the DSO and applicant, related to the feed-in tariffs and duration of operation. Adequacy of technical requirements occurs in a later step, allowing the commissioning of DGSs. Finally, insurance of the PV system should be contracted and operation may start, with at least a once-a-year meter reading by the DSO.

To establish the operation of a small power generation system (in reference to micro/minigeneration) in a grid-tied mode,

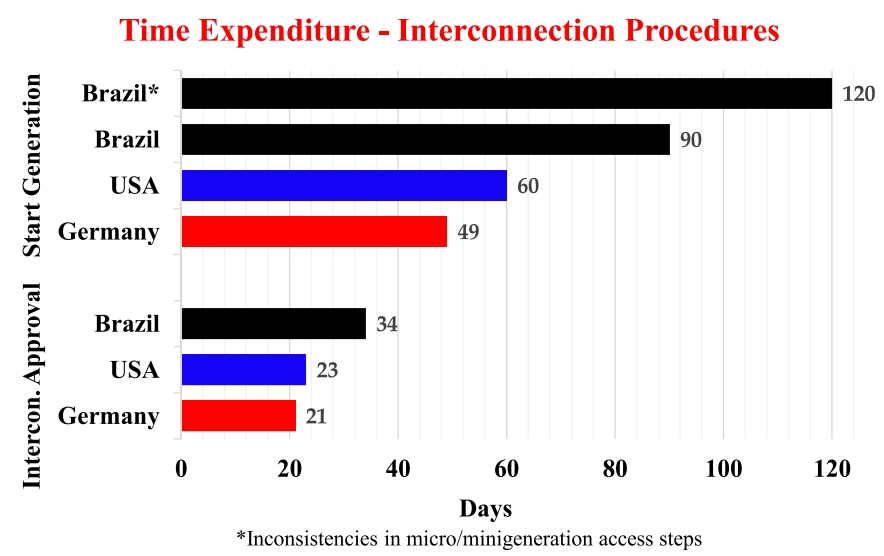

Fig. 2. Approximated timeframe comparison among Brazil, the USA, and Germany regarding interconnection procedures and microgeneration start.

American and German utilities, in general, are responsible for the most time expenditure. Similar to the Brazilian procedures, the utilities are responsible for the processes of evaluating the technical requirements of the system to be interconnected, as well as for the steps of inspecting if proper physical infrastructure and compliant equipment are being considered over all the DGS' scheme/layers (field, operation, and monitoring), as proposed in the initial application. Although the Brazilian, American, and German procedures may look generally similar, with some slightly different steps, the microgeneration application process in Brazil is much more time consuming, as depicted in Fig. 2.

One can note that the Brazilian approach takes almost 15 additional days for attaining an interconnection permit than in Germany. Furthermore, from the initial application up to the start of operation, while in Germany, it might take on average 49 days [21], in Brazil, it takes about 90 days. Moreover, it may even take 120 days if any of the four initial access stages are not rigorously followed, or there is any inconsistency.

Finally, other important point is the matter of regulatory codes for power metering with micro/minigenerators. 
Bidirectional metering is a required feature, since there will be both power injection and consumption in this scenario. Consequently, Brazilian rules define the possibility to design the generation system with a bidirectional smart meter or two other devices together that take responsibility for each way of power flow. The ANEEL rule 502/2012 [22] is responsible for the regulation of these devices, although no further discussion is herein raised.

\section{PV DeVice Regulations AND CERTIFICATION}

\section{A. Codes for Inverters}

In Brazil, there are three major rules responsible for imposing the main requirements for solar inverter's design and operation: ABNT 16149 [23], ABNT 16150 [24], and ABNT IEC 62116 [25]. This first regulation defines the requirements for solar-based utility interfaces, such as inverters, to get connected to distribution grids, later being complemented by the ABNT 16150 , which determines the conformity test procedures for those interfaces. The ABNT IEC 62116 takes into consideration specific proceedings mostly related to integrity matters, in which anti-islanding conditions need to be achieved. All these Brazilian rules are tied together by a regulatory set of rules responsible for inverter conformity, certification, and labeling, composed of the Brazilian System on Conformity Assessment (INMETRO) ordinance [26] and its updated rules [27].

Such regulations aim at defining the minimal requirements that inverters must go through in order to be recognized as a certificated device, also receiving a compliance label used on market disclosure. It is important to mention that the inverters herein discussed refer to applications in autonomous systems with a nominal power rate from 5 up to $10 \mathrm{~kW}$ and grid-tied inverters with a nominal power rate up to $10 \mathrm{~kW}$. For inverter ratings higher than $10 \mathrm{~kW}$, and up to the minigeneration limit of $5 \mathrm{MW}$, no regulations are currently applied. As a result, projects with that rating are supposed to follow whichever impositions the power utility determines for accessing its point of common coupling. Furthermore, as the market availability and prices of high power inverters are not attractive, topologies of string, multistring, and ac-module technology are generally adopted [28].

Facing a more technical side, the Brazilian compliance perspective intends to be exigent with inverter requirements. It presents some compatible features and, at the same time, other few interesting requisites not generally demanded around the world. In most of the cases, conformity certificates for the ABNT 16149, ABNT 16150, and ABNT IEC 62116 are the minimal requirements. To facilitate the understanding of such requisites for equipment designers, Fig. 3 summarizes the most essential features that an inverter must comply with to attain a certification, being complemented by Table II with the main technical considerations.

Analogously to the Brazilian scenario, many other correlated standards and regulations have been imposed on inverter certification and license to install a residential DGS around the world. In countries such as the USA, Germany, the U.K., Italy, and other Europeans/Asians, such regulations that are needed to be met are, respectively, the IEEE 1547 [29] and UL 1741 [30],

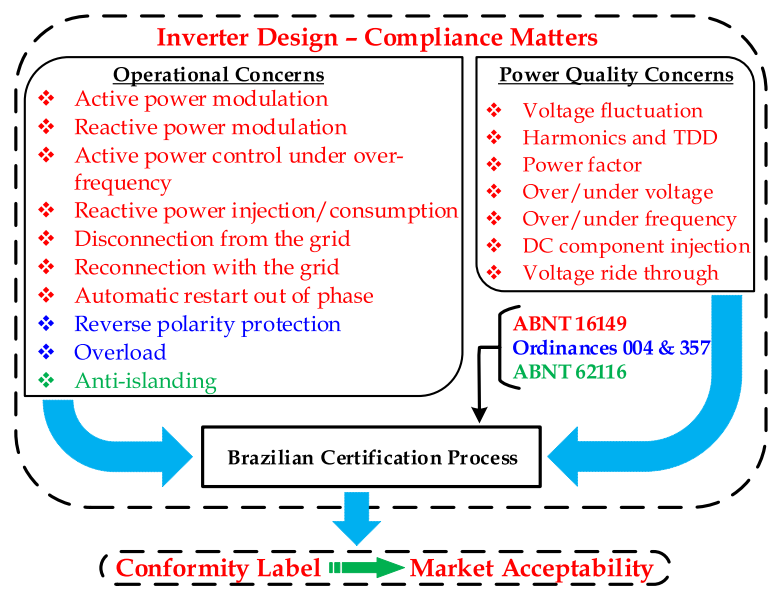

Fig. 3. Main conditions required for the design, certification, and commercialization of grid-tied inverters in Brazil.

VDE 0126-1-1 [31] and VDE-AR-N 4105 [32], GE 59 [33] and 83 [34], CEI 0-21 [14], and IEC 61727 [35]. Besides, other locally ruled codes from DSOs may be demanded. Studies such as [36]-[39] have taken into consideration the main differences among those international regulations for most of their aspects; therefore, herein, just a few contrasts related to the local perspective are risen up.

One of the primary operational conditions of a grid-connected device is the ability to adequately function within a voltage range. Consequently, once abnormal (out of the acceptable nominal range) voltages are detected, inverters are required to respond to ceasing power injection under a specific time. Fig. 4 summarizes how this condition is settled on different codes. The reference voltages are presented in a per-unit scale to facilitate the comparison. Promptly, it may be seen that the huge difference on the turn-OFF times allowed to each local, with particular levels of under- or over-voltage.

Regarding the undervoltage level, the American standard is more sensitive, starting abnormal detection from 0.88 p.u., also presenting two distinct detection zones like on the European/Asian [40] code. In Brazil, for the only zone determined, the regulation is less strict than the German rule, although the time to cease power injection is more rigid on both of them than in the U.K. or the USA. Overvoltage is taken as a more critical condition, influencing on faster turn-OFF control commands for inverters in most of the codes. Apart from the very strict imposition of the IEC code in cases over 1.35 p.u., the Brazilian code seems consistent with others in this aspect.

Ceasing of power injection under abnormal frequency conditions is another requirement, and a comparison is shown in Fig. 5. Regardless of the fact that the frequency deviates under or over the nominal values, the U.S. code again is the most exigent about the limits, and the German leads on the speed to interrupt injection. The Brazilian code is slower and allows higher frequency oscillation than most of the standards, only behind the Britain code. It is important to mention that, for this particular case, since different frequencies are adopted on the locations, being 50 or $60 \mathrm{~Hz}$, the regulated values were normalized based on each respective local nominal frequency. 
TABLE II

BRAZILIAN SPECIFICATIONS IN CODES FOR PV INVERTERS USED IN MICRO/MINIGENERATION

\begin{tabular}{|c|c|c|c|c|}
\hline Code & Feature & Specification & \multicolumn{2}{|c|}{ Condition } \\
\hline \multirow{23}{*}{ 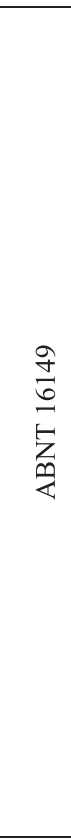 } & \multirow{3}{*}{ Abnormal Voltage Recognition } & $\mathrm{V}_{\text {grid }}<80 \%$ & \multicolumn{2}{|c|}{ Max. Turn-off: 0.4 seconds } \\
\hline & & $80 \% \leq V_{\text {grid }} \leq 110 \%$ & \multicolumn{2}{|l|}{-} \\
\hline & & $\mathrm{V}_{\text {grid }}>110 \%$ & \multicolumn{2}{|c|}{ Max. Turn-off: 0.2 seconds } \\
\hline & \multirow{4}{*}{ Abnormal Frequency Recognition } & $\mathrm{f}_{\text {grid }}<57.5 \mathrm{~Hz}$ (under) & \multicolumn{2}{|c|}{ Max. Turn-off: 0.2 seconds } \\
\hline & & $\mathrm{f}_{\text {grid }}>62 \mathrm{~Hz}$ (over) & \multicolumn{2}{|c|}{ Max. Turn-off: 0.2 seconds } \\
\hline & & \multicolumn{3}{|c|}{ When $60.5 \leq \mathrm{f}_{\text {grid }} \leq 62 \mathrm{~Hz}$ : Power is adjusted by: $\Delta P=\left[f_{\text {grid }}-\left(f_{\text {nom }}+0.5\right)\right] *(-40 \% / \mathrm{Hz})$} \\
\hline & & \multicolumn{3}{|c|}{ Reactivation may occur if : $\mathrm{f}_{\text {grid }} \geq 59.9 \mathrm{~Hz}$ (under) or $\mathrm{f}_{\text {grid }} \leq 60.1 \mathrm{~Hz}$ (over) } \\
\hline & Flicker & Short Duration: 10min & \multicolumn{2}{|l|}{ Limit: 1.0} \\
\hline & IEC61000-X & Long Duration: 2 hours & \multicolumn{2}{|l|}{ Limit: 0.65} \\
\hline & Fault Pide Throush $(\mathrm{P}, \ldots$ & $0 \% \leq V_{\text {grid }}<40 \%$ & \multicolumn{2}{|c|}{ May disconnect: 0.2 seconds } \\
\hline & Fault Ride Inrougn (Pnominal $\geq 6 \mathrm{KW}$ ) & $40 \% \leq V_{\text {grid }}<80 \%$ & \multicolumn{2}{|c|}{ May disconnect: 0.3 seconds } \\
\hline & DC Component Injection & $\geq 0.5 \%$ & \multicolumn{2}{|c|}{ Max. Turn-off: 1 second } \\
\hline & \multirow{3}{*}{ Power Factor and Reactive Power Injection } & Power $\leq 3 \mathrm{~kW}$ & \multicolumn{2}{|c|}{$\mathrm{PF}=1 /$ Limit: $0.98 \leq \mathrm{PF} \leq-0.98$} \\
\hline & & $3 \mathrm{~kW}<$ Power $\leq 6 \mathrm{~kW}$ & \multicolumn{2}{|c|}{$\mathrm{PF} \geq 0.95$ or $\mathrm{PF} \leq-0.95$} \\
\hline & & Power $>6 \mathrm{~kW}$ & \multicolumn{2}{|c|}{$\mathrm{PF} \geq 0.90$ or $\mathrm{PF} \leq-0.90$} \\
\hline & \multirow{4}{*}{ Current Harmonics and TDD } & Odd: $3^{\text {rd }}$ to $9^{\text {th }}$ & Even: $2^{\text {nd }}$ to $8^{\text {th }}$ & $<1.0 \%$ \\
\hline & & Odd: $11^{\text {th }}$ to $15^{\text {th }}$ & Even: $10^{\text {th }}$ to $32^{\text {nd }}$ & $<0.5 \%$ \\
\hline & & Odd: $17^{\text {th }}$ to $21^{\text {st }}$ & \multirow{2}{*}{\multicolumn{2}{|c|}{ TDD }} \\
\hline & & Odd: $23^{\text {rd }}$ to $33^{\text {rd }}$ & & \\
\hline & Grid Voltage Loss & \multicolumn{3}{|c|}{ If the grid voltage is absent, the inverter must stop injecting energy } \\
\hline & Reconnection & \multicolumn{3}{|c|}{ The inverter must wait between $20-300$ s to inject energy after reconnecting } \\
\hline & Automatic Grid Restart & \multicolumn{3}{|c|}{ Inverter must support this feature even under phase opposition } \\
\hline & External Control & \multicolumn{3}{|c|}{ Must support reconnection/disconnection and active/reactive control by external commands } \\
\hline 04 & Reverse Polarity & \multicolumn{3}{|c|}{ Inverter must not be damaged by reversed polarity connection } \\
\hline $\begin{array}{c}\& \\
357\end{array}$ & Overload & \multicolumn{3}{|c|}{ Inverter must handle overload conditions for short periods (about 1-3 minutes) } \\
\hline
\end{tabular}

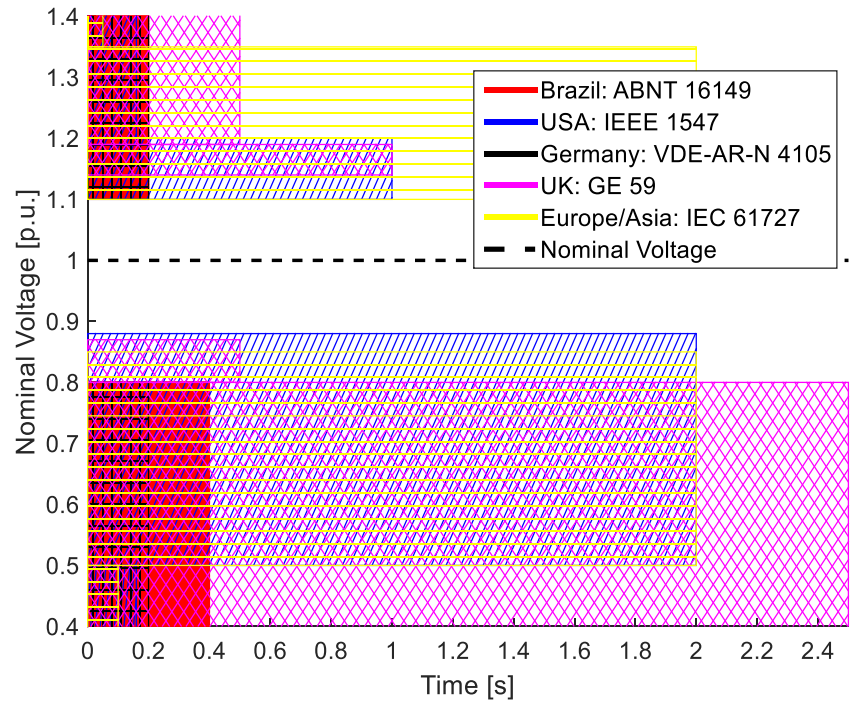

Fig. 4. Time required for inverters to cease power injection under abnormal voltage conditions in different country codes.

If at a given instant, from whichever reason, an inverter disconnects from the grid, its design is supposed to consider a reconnection process. In general, it follows a local regulated code that states a "standby" time that the inverter should wait after restoration of the voltage and frequency nominal conditions. Fig. 6 shows a comparison among countries, in which 0 s means grid restoration. On that matter, the Brazilian code identically follows the IEC standard, stating that the device should wait between 20 and $300 \mathrm{~s}$ to reconnect and reestablish power

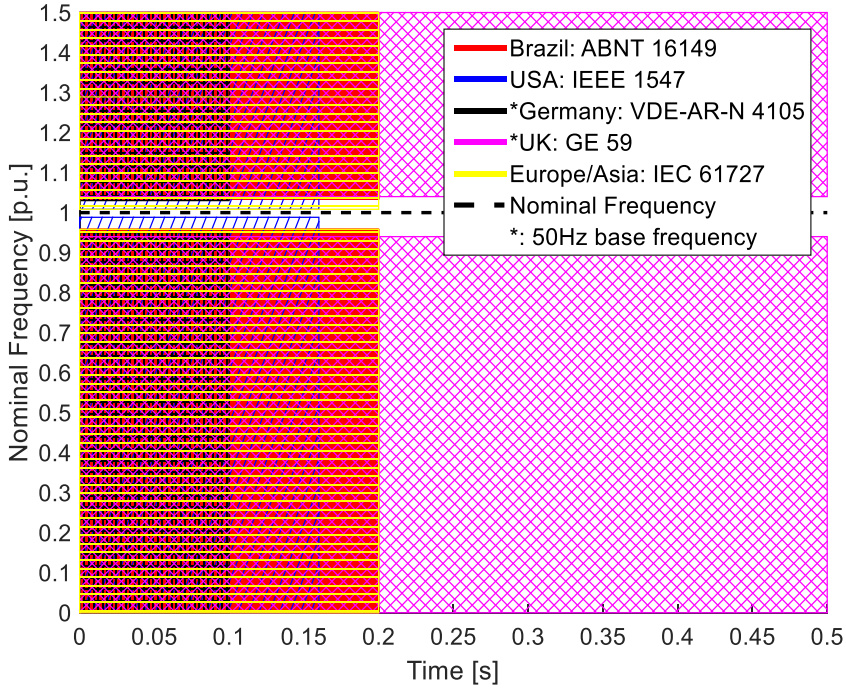

Fig. 5. Time required for inverters to cease power injection under abnormal frequency conditions in different country codes.

injection. Both of these two codes present the fastest reconnection time allowed. The American standards is the most conservative among them, allowing reconnection only after $300 \mathrm{~s}$.

Another particularity demanded for inverters in Brazil is related to the operational power factor (PF). Codes like the IEEE 1547 does not allow the inverter to adjust the PF [29], [38], but others impose that, depending on the power level, the inverter should behave within a certain region. Yet, the network operator is the one responsible for determining such characteristic curves 


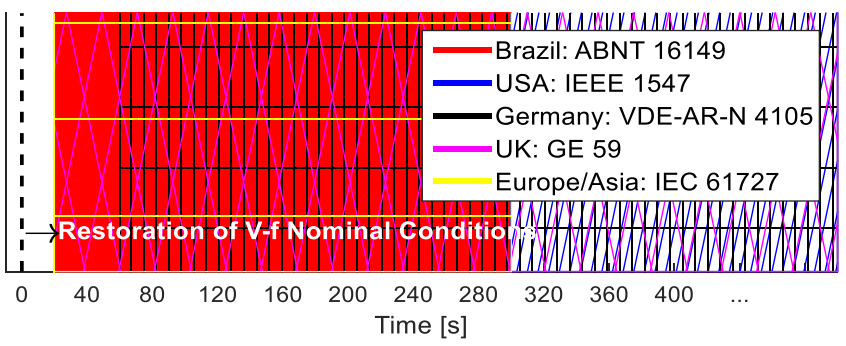

Fig. 6. Reconnection window required on different country codes.

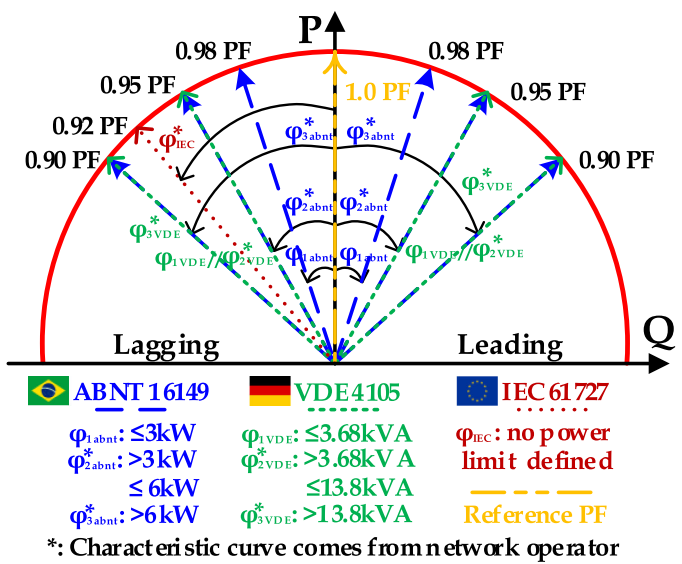

Fig. 7. PF adjustment for inverters in different country codes.

TABLE III

ANTI-ISLANDING DETECTION TIME FOR INVERTERS

\begin{tabular}{|c|c|c|c|}
\hline & Feature & Specification & Time \\
\hline \multirow{4}{*}{ 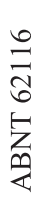 } & \multirow{2}{*}{ Voltage } & $\mathrm{V}_{\mathrm{rms}}<85 \%$ & $2 \mathrm{~s}$ \\
\hline & & $\mathrm{V}_{\mathrm{rms}}>115 \%$ & $2 \mathrm{~s}$ \\
\hline & \multirow{2}{*}{ Frequency* } & $\mathrm{f}_{\text {grid }}<58.5 \mathrm{~Hz}$ & $1 \mathrm{~s}$ \\
\hline & & $f_{\text {grid }}>61.5 \mathrm{~Hz}$ & $1 \mathrm{~s}$ \\
\hline
\end{tabular}

*Based on the local $60 \mathrm{~Hz}$ frequency

of operation. Fig. 7 gives an overview of this aspect for some rules. Note that the Brazilian is the only one requiring systems operating with power lower than $3 \mathrm{~kW}$ to obey a $\mathrm{PF}\left(\varphi_{x}\right)$ higher than 0.98. Despite that, e.g., a high similarity with the German regulation is seen.

An interesting particularity of the Brazilian codes, focused on certification of grid-tied inverters, is the requirement of two additional tests that are not present in neither the American approach of the IEEE 1547 family nor the European code within the IEC 61727. Such tests, which are the protection against reverse polarity upon an inadequate setup and the overload endurance, were imposed in the local codes for protecting consumers (small generators) under nonexpert installation service provided.

Concerning anti-islanding detection, the respective INMETRO code [25] is identical to the European IEC 62116, with a briefing of the related requirements shown in Table III.

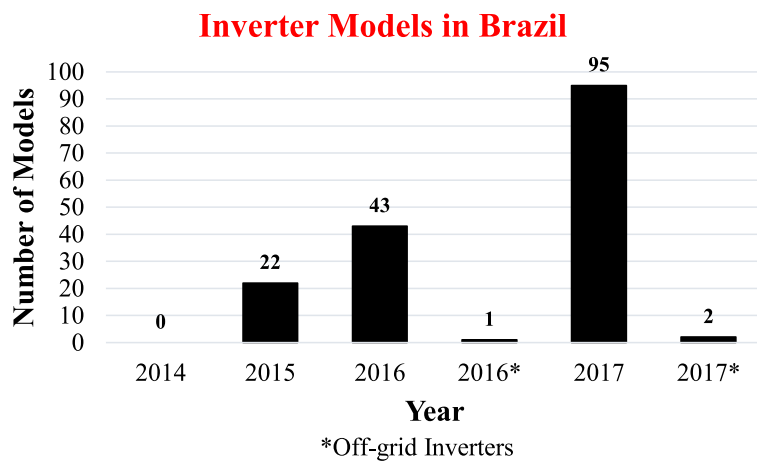

Fig. 8. Inverters models recognized with market licenses.

In terms of islanding response time under grid under/overvoltage and frequency conditions, it can be said that the local demands are similar to the American code [29], being also more rigorous than the German requisites [32]. Inverters must detect an island within a certain time and disconnect from the grid or standby not injecting power. Since the anti-islanding conditions in [25] present no innovation in relation to the well-known IEC code, which has been previously compared in other works [36], [37], [39], substantial changes are not observed for the scope of the Brazilian scenario herein mentioned.

On the unfavorable side of local particularities, there are no currently impositions on certification tests for electromagnetic interference (EMI) compatibility, or on safety matters, such as protection against electric shock, electric arc, and other tests that are within the IEC 62109 [41] or are required in the USA [42].

For instance, as a consequence, converters are not legally required to present EMI filters and endure withstanding tests [36], neither for conducted nor radiated emissions, as discussed in [43]. It is explicitly presented in [26], and not mentioned at all in its update [27], that the EMI requirements, along with matters about atmospheric electrical discharge protection, are under study for future adoption on the codes.

Taking a direction toward the market immersion of inverters, harsh and not well-published certification requirements and procedures, which, for instance, are not even widely available under the English language, restrict the market for foreign investors. Consequently, the availability of commercialized products becomes limited and detains a faster growth of the sector. As depicted in Fig. 8, in spite of the increase in the number of models recognized by INMETRO, which may be legally sold for micro/minigeneration purposes, it does not respond to the market demand intensification. The limited number of models is a result of some bureaucratic circumstances herein discussed that slow the access to new certifications and for companies to participate in the market.

One point that strengthens the discussions just raised about the commercial reality of inverters in Brazil is presented in Fig. 9. Even though many companies have a similar availability of models in the local market, as seen in Fig. 10, the overall power rating of these devices is unevenly distributed. Such ratings are densely centered on power capacities equal to or lower 


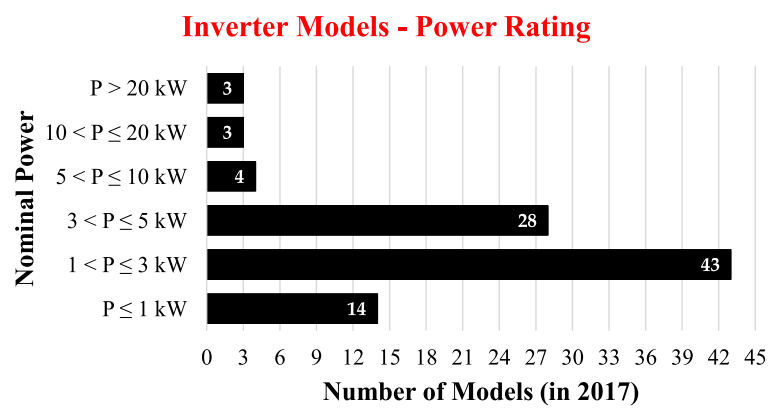

Fig. 9. Availability of grid-tied inverters models by power rating.

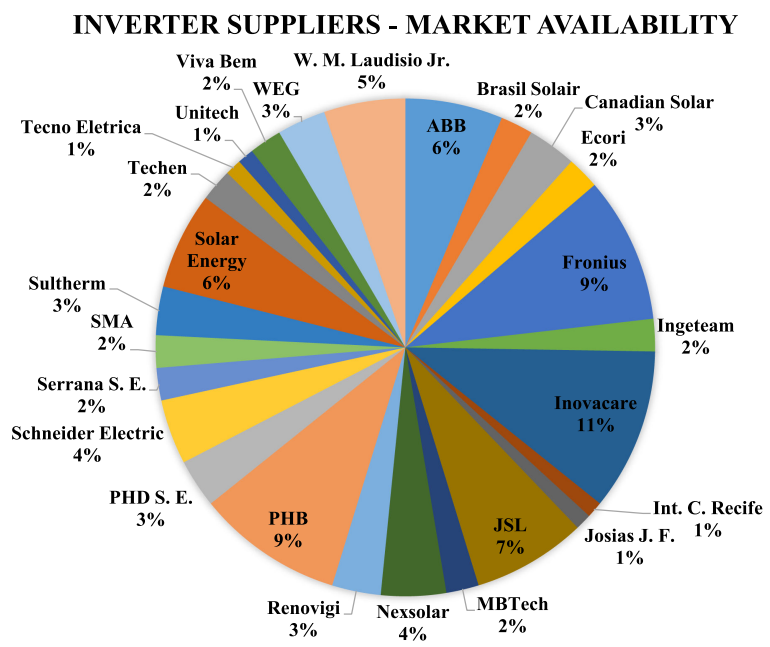

Fig. 10. Share of models on the local market and their suppliers [44].

than $5 \mathrm{~kW}$, enforcing choices to be among a few models for higher power projects, or requiring the purchase and gathering of several lower power inverters to be operated under one of the topologies aforementioned [28]. Additionally, regarding off-grid inverters for islanded applications, only two models currently present the recommended certifications on the respective codes.

Although some interesting actions have been governmentally taken intending to expand the immersion of PV micro/minigeneration in Brazil, some important inconsistencies still prevent a more efficient local market condition. Understanding that most of the development centers of inverter technologies are sited abroad, the local regulatory agency, INMETRO, issued the following instruction trying to counterbalance the market inabilities on answering to the amount of certification applications.

1) Accreditations may be conducted abroad; however, the procedures must be equivalently conducted, regarding all demands within the rules [26], [27]. Yet, the laboratory leading the experiments should be certified by the INMETRO or by an organization in which this regulator is affiliated to, such as the Inter-American Accreditation Cooperation or the International Laboratory Accreditation Cooperation.
Certified Labs for PV Equipment Certification

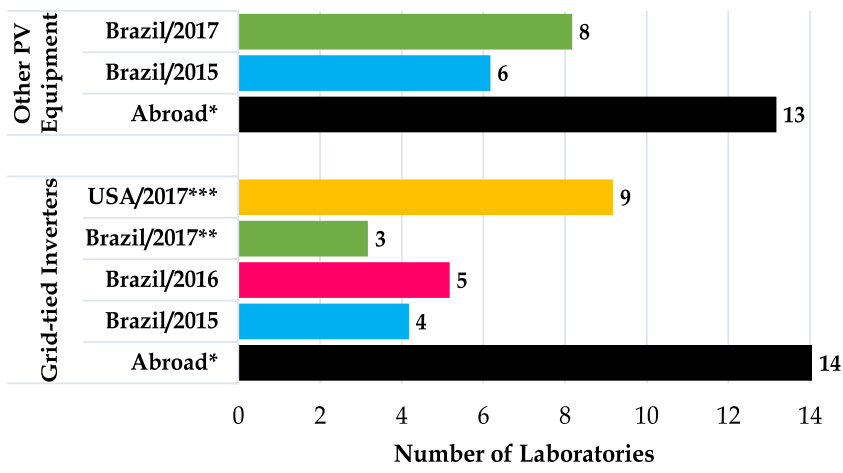

*Considering the suggested labs by INMETRO in 2016. This number is limited to all other labs abroad with the mentioned requirements.

**Current Labs: 1) IEE/USP; 2) LEP/UNESP; 3) GEPOC/UFSM

***Considering the current NRTL without their affiliated facilities

Fig. 11. Recognized laboratories by the Brazilian rules for PV equipment.

The discussion of this issue, which is one of the most critical related market obstacles, is supported by a formal acknowledgment from INMETRO [45], after being questioned by the ABSOLAR. Local and international inverter suppliers, incessantly, have faced difficulties to find authorized laboratories that are able to conduct the needed certification procedures on feasible time to attend the demand of the market. This condition also affects the requirement of attending compliance codes related to other PV equipment.

Due to the high investment required and lack of governmental incentives for the implementation of new certification laboratories, no significant rise in the number of accredited units could be noticed in the past years, as shown in Fig. 11. Besides, this scenario is even more alarming by the reason that INMETRO is constantly revaluing the already authorized laboratories, also conducting periodic conformity inspections, which may decrease the actual number of such institutions throughout a year. The revaluation and new accreditation of calibration and test laboratories in Brazil is carried out by INMETRO in accordance with the provisions in the ISO/IEC 17025:2005 code [46], where exigent requirements related to the quality of service provided are defined.

These requirements include "management requirements," with rules similar to ISO 9001, and "technical requirements" that govern matters with respect to personnel; accommodations and environmental conditions; testing, calibration, and validations methods; equipment; measurement traceability; sampling; test handling; and quality assurance of test, calibration, and presentation of results. With regard to personnel, recognized laboratories must ensure that the staff involved in accreditation activities have the knowledge of [46], along with technical training for testing and calibration methods.

Contrary to the Brazilian perspective, for instance, in the USA, a more significant number of national recognized testing laboratories (NRTL) offer inverter certification evaluations for the UL 1741 standard [13]. If the affiliated units of these laboratories (other than the headquarter) are considered, the real availability becomes even higher. 


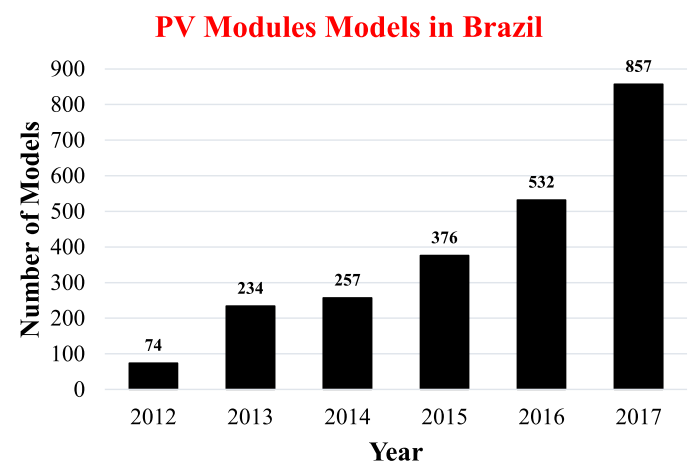

Fig. 12. PV modules recognized by INMETRO with market licenses.

TABLE IV

TESTS Required For PV MODUles IN BRAZIL

\begin{tabular}{ll}
\hline \multicolumn{1}{c}{ Tests Required } & \multicolumn{1}{c}{ Related Purpose } \\
\hline Visual Inspection & Detect visual inconsistencies on the modules \\
\hline $\begin{array}{l}\text { Performance Under } \\
\text { Nominal Operating }\end{array}$ & $\begin{array}{l}\text { Determination of electrical characteristics } \\
\text { regarding the maximum power of the modules }\end{array}$ \\
\hline Electrical Insulation & $\begin{array}{l}\text { Verifies the electrical insulation of modules' } \\
\text { terminals (+ and -) and their physical frames }\end{array}$ \\
\hline $\begin{array}{l}\text { Electrical Insulation } \\
\text { Resistance in Humid } \\
\text { Conditions }\end{array}$ & $\begin{array}{l}\text { Verifies the electrical insulation of the modules' } \\
\text { terminal (+ and }-) \text { and their frames in conditions } \\
\text { of humidity }\end{array}$ \\
\hline
\end{tabular}

Another ongoing complication is that all companies owning certified inverters on the market have to, in an annually basis, conduct a maintenance revaluation of their certifications, considering each model. This directly affects the Brazilian DGS perspective, in a positive way, by being strict and allowing only compliant devices to be commercialized, but, on the negative side, making the accessibility to certification institutions even more restricted and expensive for suppliers to sell their products.

\section{B. Codes for Other PV Equipment}

Within the Brazilian regulations 04 and 357, parameters for the adequacy of other PV equipment are also established, comprising instructions for the regulation of PV modules, battery charge controllers, and batteries. It is highlighted that batteries are not addressed in this paper, due to the need of more extensive discussions. Concerning PV modules, the exponential increase of the market availability, as a result of the rising DGS scenario, is depicted in Fig. 12.

To obtain a certification recognition from INMETRO, suppliers of PV modules must submit two samples of their product model to undergo only a few particular experimentations determined inside the European standards IEC 61215-1 [47] and IEC 61646 [48]. Table IV briefly summarizes the four tests required and their purposes for labeling PV modules in Brazil. As can be clearly seen in Brazil, the PV module certification tests are significantly less strict than the inverter labeling program, allowing laboratories to attend the market more adequately. This also justifies the discrepancy in comparing the market availability of
TABLE V

TESTS REQUiRED FOR BATTERY CHARGE CONTROLLERS IN BRAZIL

\begin{tabular}{|c|c|}
\hline Tests Required & Tests Required \\
\hline \multirow{4}{*}{ (PUNOC) } & Voltage Drop \\
\hline & $\begin{array}{l}\text { Voltage upon disconnection on PV module replacement } \\
\text { and temperature compensation }\end{array}$ \\
\hline & Voltage upon disconnection on load replacement \\
\hline & Current self-consumption \\
\hline \multirow{5}{*}{ (PUEOC) } & $\begin{array}{l}\text { Protection against overvoltage on PV module input } \\
\text { connectors }\end{array}$ \\
\hline & Protection against reverse polarity on PV module \\
\hline & Protection against reverse polarity on battery connectors \\
\hline & $\begin{array}{l}\text { Protection against reverse connection regarding battery } \\
\text { and PV module }\end{array}$ \\
\hline & $\begin{array}{l}\text { Protection against short-circuit on the output terminals } \\
\text { for load }\end{array}$ \\
\hline
\end{tabular}

models between inverters and PV modules. A large variety of power ratings is found on commercialized panels, ranging from $5 \mathrm{~W}$ up to, approximately, $500 \mathrm{~W}$.

Looking at the negative side of this case, it is notable that the certification tests required for attaining a market recognition in Brazil are still underestimated. Although the four proposed experimentations follow the well-established IEC 61215, around the world, this standard establishes many other test procedures for compliance assessment. Another matter refers to the technologies commercialized in Brazil. Currently, although many models of PV panels are locally saleable, not many diversified possibilities regarding PV generation technologies [49] are available on the market or are adopted on energy biddings, being basically composed of crystalline silicon and thin-film panels. Safety matters (e.g., specifications for materials used on the panel construction, electrical, mechanical and thermal hazards evaluation, and other endurance tests) are also ignored by Brazilian codes, different from what is demanded in Europe, for instance, through the IEC 61730 standard [50].

Even though the local codes for PV devices also rule the adequacy of battery charge controllers, this is the only topic, entirely, neither based nor related to any local or international standard or code. Such a circumstance may be justified by the more common use of these devices in PV systems based on islanded operation, therefore not direct impacting grid-tied systems and drawing less governmental attention.

Diverging from international standards, such as [51], which require tests related to battery lifetime protection, energy performance, physical hazards, and fail safe abilities, as well as user interface demands, the Brazilian rule is superficial. It only requires tests needed for general operation of charge controllers, being performed under nominal operating conditions (PUNOC), and performed under extreme operation conditions (PUEOC), as summarized in Table V.

A similar interpretation on the PV module perspective can be done on the matter of market accessibility for battery charge controllers. As regulations are not strict due to the tendency of applying this technology to noninterconnected systems, and 
the adequacy tests for certifications are fast to be performed, a large availability of products are commercialized, attending diversified applications and offering operation under several power ratings.

\section{CONCLUSION}

Brazilian regulations for microgenerators and inverter certification have been facing significant adjustments and updates for the past few years. In this context, this work presents the interconnection procedures defined by the ANEEL, which should be followed by utilities and prosumers, and also, it highlights some contrasts when compared to the American and German perspectives on interconnection regulations. With regard to power inverters, the main certification tests and requirements for having a market recognizable product were discussed. Moreover, several comments regarding the availability of products on the market and how their commerce is distributed have been presented.

The current PV module certification methods and market acceptability showed that, although the market demand is increasing, several changes are expected for the local future perspective. Finally, summarizing the discussions, it is possible to note that the Brazilian regulation and resolutions are progressing, although significant improvements are still needed in order to reach the level of service and compliance of electrical regulations as settled in other leading countries.

Thus, considering all previous discussions, the Brazilian micro/minigeneration scenario may be seen as an opportunity for many adjustments and improvements for a more robust sector, and, in special, a more attractive and dynamic market for energy investors and companies.

\section{REFERENCES}

[1] EIA, "International energy outlook," U.S. Dept. Energy, Washington, DC, USA, Tech. Rep. DOE/EIA-0484(2017), Sep. 2017.

[2] REN21, Renewables 2017-Global Status Report. Paris, France: REN21 Secretariat, Oct. 2017.

[3] G. Platt, S. West, and T. Moore, "The real-world challenges and opportunities of distributed generation," in Proc. IEEE Energy Convers. Congr Expo., 2015, pp. 1112-1116.

[4] M. G. Godoy et al., "A comparison of smart grid technologies and progresses in Europe and the U.S.," IEEE Trans. Ind. Appl., vol. 48, no. 4, pp. 1154-1162, Jul./Aug. 2012.

[5] T. Caldognetto, P. Tenti, A. Costabeber, and P. Mattavelli, "Improving microgrid performance by cooperative control of distributed energy sources," IEEE Trans. Ind. Appl., vol. 50, no. 6, pp. 3921-3930, Nov./Dec. 2014.

[6] Ministry of Mining and Energy (MME), "Proposal to improve the legal framework of the electric sector-Technical note," (in Portuguese), MME, Brasilia, Brazil, Tech Rep. 05/2017, Jul. 2017.

[7] EPE-MME, "10-year Energy Expansion Plan PDE 2026" (in Portuguese), MME, Brasilia, Brazil, Tech. Rep., 2017. [Online]. Available: http://www.epe.gov.br/PDE/Documents/Arquivos/PDE2026/PDE2026_ versao_para_ConsultaPublica.pdf

[8] A. M. S. Alonso et al., "PV microgeneration perspective in Brazil: Approaching interconnection procedures and equipment certification," in Proc. 9th Annu. IEEE Green Technol. Conf., 2017, pp. 67-74.

[9] ANEEL Resolution $\mathrm{N}^{\circ}$ 482, ANEEL Rule 482 (in Portuguese), Apr. 2012.

[10] ANEEL Resolution $N^{\circ}$ 687, ANEEL Rule 687 (in Portuguese), Nov. 2015.

[11] ANEEL Resolution N 733, ANEEL Rule 733 (in Portuguese), Nov. 2016.

[12] B. Barth, J. Mayer, N. Trennepohl, and R. Bruckmann, "Framework assessment for the photovoltaic business opportunities in Brazil," BSW-Solar eclareon GmbH, Berlin, Germany, Tech. Rep, Jul. 2014. [Online]. Available: https://www.eclareon.com/sites/default/ files/pvframework_brazil.pdf
[13] Recommendations for Utility Communications with Distributed Energy Resources (DER) Systems with Smart Inverters, CPUC Rule 21 - Draft v9, Feb. 2015.

[14] Technical Rule for the Connection of Active and Passive Users to LV Networks of Distributors of Electricity (in Italian), CEI-0-21 Standard, Jul. 2016.

[15] R. Hanna, M. Leach, and J. Torriti, "Microgeneration: The installer perspective," Renew. Energy, vol. 116, pp. 458-469, Sep. 2017.

[16] M. Goel, "Solar Rooftop in India: Policies, challenges and outlook," Green Energy Environ., vol. 1, no. 2, pp. 129-137, Jul. 2016.

[17] ANEEL Resolution Nº 395, ANEEL Rule 395 (in Portuguese), Dec. 2009.

[18] Access to the Distribution System, ANEEL-PRODIST 3rd Module (in Portuguese), Jun. 2017.

[19] Electric Power Quality, ANEEL-PRODIST 8th Module (in Portuguese), Jun. 2017.

[20] Model Interconnection Procedures, IREC-Interstate Renewable Energy Council Procedures, Apr. 2013.

[21] P. V. Grid, Germany: Household Rooftop PV Systems, 2017. [Online]. Available: http://www.pvgrid.eu/database/pvgrid/germany/nationalprofile-6/residential-systems/2404/household-rooftop-pv-systems1/grid-connection-permit-4.html

[22] ANEEL Resolution N 502, ANEEL Rule 502 (in Portuguese), Aug. 2012.

[23] Photovoltaic (PV) Systems-Characteristics of the Interface Connection with the Electric Distribution Grid (in Portuguese), ABNT NBR Standard 16149, Mar. 2013.

[24] Photovoltaic (PV) Systems-Characteristics of the Interface Connection with the Electric Distribution Grid-Conformity Test Procedures (in Portuguese), ABNT NBR Standard 16150, Mar. 2013.

[25] Anti-Islanding Test Procedures for Grid-tied Photovoltaic System Inverters (in Portuguese), ABNT IEC Standard 62116, Mar. 2012.

[26] Ordinance $\mathrm{N}^{\circ} 004$ (in Portuguese), INMETRO, Rio de Janeiro, Brazil, Jan. 2011.

[27] Ordinance $\mathrm{N}^{\circ} 357$ (in Portuguese), INMETRO, Rio de Janeiro, Brazil, Aug. 2014.

[28] S. B. Kjaer, J. K. Pedersen, and F. Blaabjerg, "A review of singlephase grid-connected inverters for photovoltaic modules," IEEE Trans. Ind. Appl., vol. 41, no. 5, pp. 1292-1306, Sep./Oct. 2005.

[29] IEEE Standard for Interconnecting Distributed Resources with Electric Power Systems, IEEE Standard 1547, Jul. 2003.

[30] Standard for Inverters, Converters, Controllers and Interconnection System Equipment for Use with Distributed Energy Resources, UL 1741 Standard, Jan. 2010.

[31] Automatic Disconnection Device Between a Generator and the Public Low-Voltage Grid, VDE 0126-1-1 Standard, Aug. 2013.

[32] Power Generation Systems Connected to the Low-Voltage Distribution Network, VDE-AR-N 4105 Standard, Aug. 2011.

[33] Recommendations for the Connection of Generating Plant to the Distribution Systems of Licensed Distribution Network Operators, Eng. Recommendation G59, Aug. 2014.

[34] Recommendations for the Connection of Type Tested Small-scale Embedded Generators (up to $16 \mathrm{~A}$ per phase) in Parallel with Low-Voltage Distribution Systems, Eng. Recommendation G83, Dec. 2012.

[35] Standard Photovoltaic (PV) Systems - Characteristics of the Utility Interface, IEC Standard 61727, Dec. 2009.

[36] Y. Wu, J. Lin, and H. Lin, "Standards and guidelines for grid-connected photovoltaic generation systems: A review and comparison," IEEE Trans. Ind. Appl., vol. 53, no. 4, pp. 3205-3126, Jul./Aug. 2017.

[37] Y. Yang et al., "Wide-scale adoption of photovoltaic energy: Grid code modifications are explored in the distribution grid," IEEE Ind. Appl. Mag., vol. 21, no. 5, pp. 21-31, Jun. 2015.

[38] L. Schwartfeger and D. Martin, "Review of distributed generation interconnection standards," in Proc. EEA Conf. Exhib., 2014, pp. 1-13.

[39] H. H. Figueira et al., "Brazilian grid-connected photovoltaic inverters standards: A comparison with IEC and IEEE," in Proc. IEEE Int. Symp. Ind. Electron., 2015, pp. 1104-1109.

[40] N. Chimres and S. Wongwises, "Critical review of the current status of solar energy in Thailand," Renew. Sustain. Energy Rev., vol. 58, pp. 198207, May 2016.

[41] Safety of Power Converters for Use in Photovoltaic Power Systems-Part 1: General Requirements, IEC Standard 62109-1, Apr. 2010.

[42] A. S. Mundada et al., "A review of technical requirements for plug-andplay solar photovoltaic microinverter systems in the United States," Sol. Energy, vol. 135, pp. 455-470, Oct. 2016.

[43] D. Dong et al., "A PV residential micro-inverter with grid-support function: Design, implementation and field testing," IEEE Trans. Ind. Appl., vol. 54, no. 1, pp. 469-481, Jan./Feb. 2018. 
[44] INMETRO, "National labeling program: PV components - on grid inverters," (in Portuguese), INMETRO, Rio de Janeiro, Brazil, Tech. Rep., Mar. 2017. [Online]. Available: http://www.inmetro.gov.br/ consumidor/pbe/componentes_fotovoltaicos_Inversores_On-Grid.pdf

[45] Ordinance $\mathrm{N}^{\circ}$ 17, INMETRO (in Portuguese), Jan. 2016.

[46] General Requirements for the Competence of Test and Calibration Laboratories (in Portuguese), ABNT NBR 17025:2005, Dec. 2017.

[47] Terrestrial Photovoltaic (PV) Modules-Design Qualification and Type Approval, IEC 61215 Standard, Mar. 2016.

[48] Thin-Film Terrestrial Photovoltaic (PV) Modules-Design Qualification and Type Approval, IEC Standard 61646, May 2008.

[49] O. Ogbomo et al., "A review of photovoltaic module technologies for increased performance in tropical climate," Renew. Sustain. Energy Rev., vol. 75 , pp. 1225-1238, Nov. 2017.

[50] Photovoltaic (PV) Module Safety Qualification-Part 1: Requirements for Construction, IEC 61730-1 Standard, Aug. 2016.

[51] Battery Charge Controllers for Photovoltaic Systems-Performance and Functioning, IEC 62509 Standard, Dec. 2010.

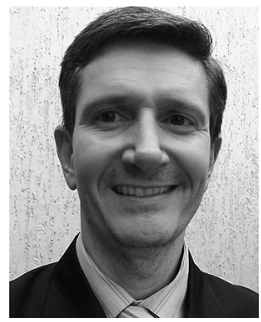

Fernando Pinhabel Marafão (S'95-M'05) received the B.S. degree in electrical engineering from the Universidade Estadual Paulista (UNESP), Sorocaba, Brazil, in 1998, and the M.Sc. and Ph.D. degrees from the University of Campinas, Campinas, Brazil, in 2000 and 2004, respectively.

In 2002, he joined the Power Electronics Group, University of Padova, Padova, Italy, as a Visiting Student. In 2013, he joined the ACEPS Group, Colorado School of Mines, Golden, CO, USA, as a Visiting Scholar. He is currently an Associate Professor with UNESP, where he has been teaching and leading several research projects since 2005. His research interests include power conditioning, renewable energies, and smart grids.

Dr. Marafão is a member of the Brazilian Power Electronics Society and the Brazilian Automatic Society.

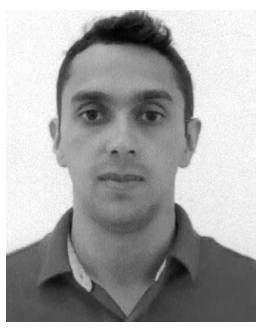

Augusto Matheus dos Santos Alonso (S'16) received the B.S. degree in automation and control engineering from the Federal University of Ouro Preto, Ouro Preto, Brazil, in 2014 (with a sandwich period as a BSMP Scholar at the University of New Mexico, Albuquerque, NM, USA, between 2012 and 2013), and the M.S. degree in electrical engineering from Universidade Estadual Paulista, Sorocaba, Brazil, in 2018, where he is currently working toward the Ph.D. degree.

His main research interests include coordinated control of grid-tied converters, hierarchical microgrid control, power quality, and energy policies.

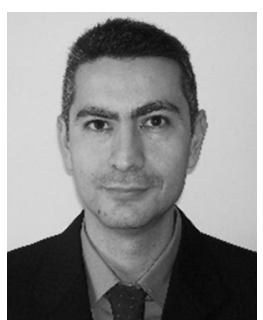

Flávio A. S. Gonçalves received the B.S., M.S., and $\mathrm{Ph} . \mathrm{D}$. degrees in electrical engineering from Universidade Estadual Paulista (UNESP), Sorocaba, Brazil, in 1998,2001 , and 2005, respectively.

From 2008 to 2010, he was an Assistant Professor with the Department of Electrical Engineering, School of Engineering, UNESP, Ilha Solteira, Brazil. Since 2010, he has been an Assistant Professor with UNESP, Sorocaba. In 2011, he was a Visiting Professor with the University of Padova, Padova, Italy. His research interests include power quality, active power factor correction, association techniques for converters, nondissipative switching techniques, dc-dc and ac-dc converters, electronic drive for electric machines, power storage, and distributed platforms for E-Learning in power electronics.

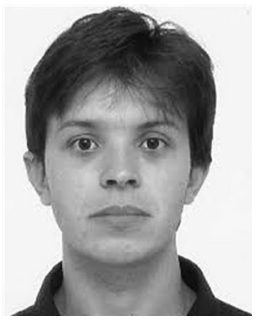

Danilo Iglesias Brandão (S'14-M'16) received the B.S. degree in control and automation engineering from the Universidade Estadual Paulista, Sorocaba, Brazil, in 2011, and Doctoral degree in electrical engineering from the University of Campinas, Campinas, Brazil, in 2015 .

He was a Visiting Scholar with the Colorado School of Mines, Golden, CO, USA, in 2009 and 2013, and with the University of Padova, Padova, Italy, in 2014. He is currently an Assistant Professor with the Department of Electrical Engineering and with the Graduate Program in Electrical Engineering, Federal University of Minas Gerais, Belo Horizonte, Brazil. His main research interests include control of grid-tied converters, power quality, power theories, and microgrids.

Dr. Brandao is a member of the Brazilian Power Electronics Society.

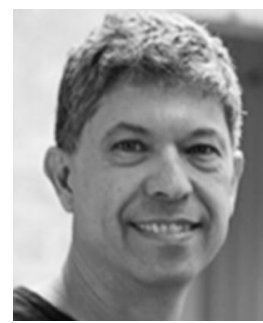

Antonio Cesar Germano Martins received the B.S degree in physics from the University of Campinas, Campinas, Brazil, in 1989, and the M.S. degree in physics and the Ph.D. degree in electrical engineering from the University of São Paulo, São Paulo, Brazil, in 1993 and 1997, respectively.

Since 2004, he has been a Professor with the Institute of Science and Technology, Universidade Estadual Paulista, Sorocaba, Brazil, where he works with the Group of Automation and Integrated Systems. His research interests include energy matrices and sustainable energy sources. es.

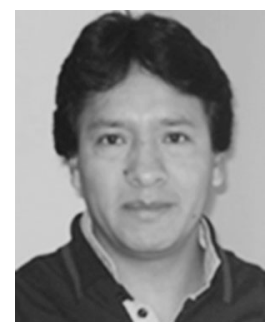

Helmo Kelis Morales Paredes (S'10-M'11-SM'18) received the B.S. degree from the San Agustin National University Arequipa, Arequipa, Peru, in 2002, and the M.Sc. and Ph.D. degrees from the University of Campinas, Campinas, Brazil, in 2006 and 2011, respectively, all in electrical engineering.

In 2009, he joined the Power Electronics Group, University of Padova, Padova, Italy, as a Visiting Student. In 2014, he joined the PEMC Group, University of Nottingham, Nottingham, U.K., as a Visiting Scholar. In 2018, he joined the ACEPS Group, Colorado School of Mines, Golden, CO, USA, as a Visiting Scholar. Since December 2011, he has been an Assistant Professor with Universidade Estadual Paulista, Sorocaba, Brazil, where he is the leader of the Group of Automation and Integrating Systems. His current research interests include power quality, power theories, and power electronics.

Dr. Morales Paredes is a member of the Brazilian Power Electronics Society and the Brazilian Automatic Society. He received a Prize Paper Award from the IEEE TRANSACTIONS ON POWER ELECTRONICS in 2011. 